\section{The Diversity in Performance of Commercial Olive Clones Selected from the Autochthonous cv. Souri Population for Intensive Irrigated Cultivation}

\author{
Giora Ben-Ari ${ }^{1}$ \\ Institute of Plant Science, Volcani Center, ARO, Bet-Dagan, Israel; and the \\ Faculty of Agriculture, HUJI, Rehovot, Israel
}

Iris Biton, Yair Mani, and Benjamin Avidan

Institute of Plant Science, Volcani Center, ARO, Bet-Dagan, Israel

\author{
Shimon Lavee \\ Institute of Plant Science, Volcani Center, ARO, Bet-Dagan, Israel; and the \\ Faculty of Agriculture, HUJI, Rehovot, Israel
}

Additional index words. clonal selection, irrigated cv. Souri, olive

\begin{abstract}
The performance of five cv. Souri selections designated as "clones" were compared in two consecutive plots for $\approx 20$ years each and three additional ones for 18 years. Fruit morphology, yield, oil production, and tree growth were monitored. The major results are presented as mean values of five sequential "on" years as well as the characteristic production of young and mature trees. The DNA identity was determined using both simple sequence repeats (SSRs) and single nucleotide polymorphisms (SNPs). The performance of two "clones," SLO and SBU, showed stable diverse production characteristics and could be designated as defined clones, although no clear differences of the DNA between them or the other "clones" were apparent. Another "clone," SGS, was also designated as a true clone as a result of both unique fruit morphology and DNA markers. The differences between the other "clones" were minute in fruit production morphology and oil production as well as on a DNA basis and their designation as being true clones is doubtful.
\end{abstract}

The Souri cultivar, which is autochthonous to the eastern Mediterranean region, is the major olive variety cultivated traditionally under rain-fed conditions in Israel for hundreds of years. Even today, this cultivar occupies approximately two-thirds of the olive-planted area in the country and is based on rain-fed traditional cultivation. The cv. Souri is characterized by its high adaptability to semiarid conditions and occasional droughts, shallow and stony marginal soils, and varying climatic conditions (Jbara et al., 2010; Omar, 2012). Generally its fruit has a high aromatic oil content reaching up to $30 \%$ in commercial extraction (Goor, 1948). The cv. Souri olives are also highly appreciated as green natural fermented table olives, particularly because of their firm grainy aromatic mesocarp. Thus, cv. Souri trees were traditionally planted for generations around the villages in most regions of the country regardless of the local different and occasionally unfavorable environmental conditions in some of the locations. As a result of generations of planting and replanting of this

Received for publication 5 Nov. 2013. Accepted for publication $21 \mathrm{Feb} .2014$.

${ }^{1}$ To whom reprint requests should be addressed; e-mail giora@agri.gov.il. cultivar in the various regions and environments, a high variability between trees of this cultivar developed. A survey of the trees in a wide range of the traditional rain-fed orchards resulted in identifying more than 15 morphological or developmental different types when compared under uniform growing conditions in the Hannania farm experiment at the lower Galilee (Lavee et al., 2008). Eleven of those were tested for their genetic identity using random amplified polymorphic DNA polymerase chain reaction methodology used for the other major autochthonous cv. Nabali (Lavee et al., 1999), and at least three defined groups were clearly visible. Based on the high variability within the 'Souri' tree population on both morphologic and genetic criteria, it was suggested to refer to that traditional cultivar as the "cv. Souri family." It should be noted that all the different 'Souri' types are relative good producers under rain-fed cultivation conditions through defined alternate bearers (Lavee, 2007). With the introduction of intensive cultivation and irrigation to the newly developing olive oil industry (Grattan et al., 2006; Greven et al., 2009), it became apparent that the 'Souri' trees do not respond enough to the intensive cultivation. This is probably the result of generation of selection for adaptation of the Souri cultivar to limiting growth conditions. Although its yield doubled in most cases under intensive cultivation reaching long-term average yields of 6 to 8 tons fruit per hectare, its response to intensification and irrigation was still lower than that of various other cultivars. Because its oil and processed fruit are highly appreciated by the Israeli population, various selections were made in the country expected to be more responsive to intensification. "Clonal" propagated plants of these selections were distributed by the nurseries to many of the new intensive olive orchards planted during the last decades in Israel.

In the present study, the cultivation response, morphology, fruit development, production, and genetic identity of these "clones" planted and grown under uniform irrigated conditions were analyzed over different periods of time in three independent plots. The plots were located at the experimental farm of the Volcani center in the center of the Israeli coastal plane. This is the first study characterizing these clones from both the morphological and genetics points of view.

\section{Materials and Methods}

Vegetative propagated plants of five selected cv. Souri commercial "clones" were planted under intensive irrigated conditions in early 1974 at the Bet Dagan research institute and kept until 1998 (Plot A). Plot A was planted in a density of $4 \times 6 \mathrm{~m}$ and was irrigated with $500 \mathrm{~mm}$ drip irrigation per year on top of a mean of $430 \mathrm{~mm}$ annual rain. A second plot with nine "clones" including the five "clones" planted in the first plot was planted in a density of $6 \times 6 \mathrm{~m}$ in 1995-96 and kept until 2013 with the same irrigation scheme (Plot B). Six plants of each clone were planted in the first plot and three in the second in which were planted also some selected clones of other local autochthonous cultivars. A third plot (Plot C) consisting of one clone only, Souri Lod (SLO), was planted in 1984 for comparison of fruit growth and oil accumulation under rain-fed and irrigated conditions. The different "clones" used were selected in traditional orchards at different regions of Israel and each designated with a special code (Table 1). Fruit and oil yields were recorded in most cases only during "on" years unless indicated differently. Fruit growth, percent dry matter, and the oil content were determined for three sample clones at weekly intervals during the growing season from the beginning of June until the second half of November. Mean fruit yield, fresh fruit size, percent pulp dry weight, percent stone, oil content on a dry weight basis, and the commercial oil content were calculated for each "clone" separately in both plots. The consistency of the fruit characteristics of the different "clones" with aging of the trees was determined for all "clones" in Plot B by comparing the results of fruit analyzed in Year 2000 with those performed 12 years later in 2012.

Statistical significant differences in the analysis of variance tests were based on $2.5 \times \mathrm{SE}$.

Verification of morphological, developmental, and production differences between the "clones" on a genetic basis was 
performed using both the SSR methodology based on 16 SSR loci used in our last study (Biton et al., 2012) and a SNP analysis based on 138 loci.

SNPs genotyping. Genomic DNA libraries were prepared from DNA of the cultivars Barnea and Manzanillo using Illumina's TruSeq DNA kit according to the manufacturer's instructions and sequenced on Illumina HiSEq. 2000 using a V3 flow cell, 100-bp single read, and one index-read run. A total of 145,000 SNPs was identified. We genotyped all clones against 192 SNP loci, chosen from the 145,000 discovered. Large-scale genotyping of SNPs was performed on four Fluidigm 96.96 Dynamic Arrays using the genotyping EP1 System (San Francisco, CA). Fluorescence intensity was measured with the EP1 (Fluidigm Corp., San Francisco, CA) reader and plotted on two axes. Genotypic calls were made using the Fluidigm SNP Genotyping Analysis program. From the 192 genotyped SNPs, only 138 were suitable for analysis, mainly as a result of technical problems.

The list of SNPs is available on request from the authors.

To assess the genetic relationship between olive accessions, we estimated the genetic distance as $\mathrm{D}=1$ - proportion of shared alleles (PSA). PSA was calculated as

$$
P S A=\frac{\sum_{i=1}^{L} P S_{i}}{2^{*} L}
$$

where PS is the proportion of shared alleles for each locus and $\mathrm{L}$ is the total number of loci (Bowcock et al., 1994).

A hierarchical clustering was performed on a pairwise $\mathrm{D}$ as a distance matrix using an agglomerative method called "ward" (Odong et al., 2011). To reinforce our results of tree topology, a resampling of 1000 times was run on loci to create 1000 SNP sets and 1000 trees. To count the number of bipartitions that fit the tree, we used the "ape" R-package (Paradis et al., 2004; Popescu et al., 2012). The bootstrap values are presented as percentages.

\section{Results}

Different cv. Souri "clones" were tested in this study. Oil accumulation started in fruit of the rain-fed trees at a somewhat higher level than in fruit of the irrigated ones but continued at the same rate until the end of August when it increased in the rain-fed fruit reaching a maximum in mid-October. In this particular case, the oil content in fruit of irrigated trees reached the same level but $\approx 1$ month later.

A comparison of fruit growth, accumulation of dry matter, and oil during an "on" growing season under irrigated conditions was performed on trees of three cv. Souri "clones" of the five grown in Plot A, SLO, Souri Amka (SAM), and Souri Buchbinder (SBD) (Fig. 1). Fruit growth proceeded at the about the same rate on the trees of all three "clones" until mid-September; thereafter, the fruit growth on the three different "clones" diverted. The growth rate of SLO and SBD fruits increased, whereas that of SAM remained rather constant. Toward the end of November

Table 1. Origin and code designation of the commercial cv. Souri olive "clones" tested in the different central plots A, B, and C.

\begin{tabular}{rllll}
\hline & Souri clones & \multicolumn{1}{c}{ Origin } & Code & Plot \\
\hline 1 & Latrun & Central foothills & SLR & B \\
2 & Lod & Coastal plain & SLO & ABC \\
3 & Amka & Northwest foothills & SAM & AB \\
4 & Dir-Haana & Galilee mountains & SDH & B \\
5 & Buchbinder & North central inland & SBU & AB \\
6 & Bet-Dagan & Galilee central valley & SBD & AB \\
7 & Gat-Shemanim & Jerusalem mountains & SGS & B \\
8 & Hanania-1 & Galilee mountains & SH-1 & AB \\
& & Other local cultivars & & \\
9 & Fadel & Galilee central valley & FAD & B \\
10 & Baladi & Lebanon & BAL & B \\
11 & Nabali & Central Samaria mountains & NBD & B \\
\hline
\end{tabular}
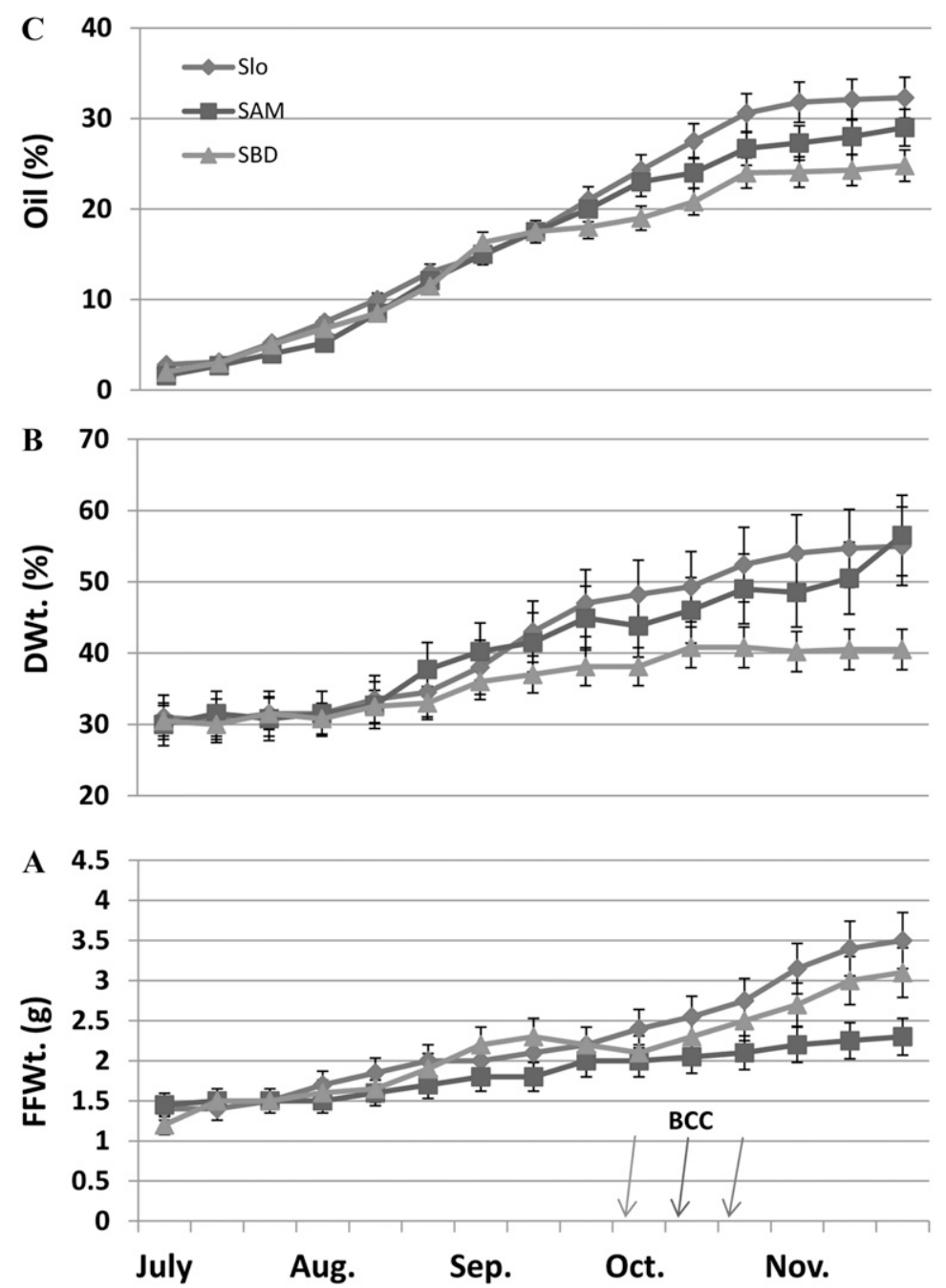

Fig. 1. Fruit growth (A), dry weight $(\mathbf{B})$, and oil accumulation $(\mathbf{C})$ during the growing season in fruit of three cv. Souri "clones," SLO, SAM, and SBD, under irrigated growing conditions in the midcoastal plain of Israel. The arrows indicate the beginning of color change (BCC).

the fruit of SLO was the largest, that of SBD slightly smaller, and that of SAM significantly the smallest (Fig. 1A). The fruit growth, however, was not related to their ability to accumulate metabolites, dry matter, and oil. A reduced rate of dry matter accumulation in fruit of the SBD "clone" was noticed already in mid-August. Approximately 1 month later also oil accumulation in fruit of this "clone" started to drop off. Fruit of SLO, which showed the highest growth rate, also accumulated more quickly dry matter and reached a final higher oil content on a fresh weight basis than the fruit of the other two "clones" (Fig. 1B-C). It should be noted that until the beginning of September, the rate of oil accumulation in the fruits of all three "clones" on a fresh weight basis was the same. 
Five commercially selected cv. Souri "clones" for irrigated cultivation were planted as early as 1974 in a uniform comparison plot in the Israeli coastal plain at BetDagan and cultivated for 20 years until 1994 (Plot A). A second plot also under irrigation was planted next to the Bet-Dagan national olive collection in 1996 and is kept to the present (Plot B). The second plot included the five "clones" compared in the first plot, one additional commercial "clone," two later planted entries, and a cv. Nabali type used occasionally for comparison. A morphological fruit comparison of the eight cv. Souri "clones" from the second plot revealed a basic similarity between the different accessions except for the Gat-Shmanim "clone" (SGS). Although the fruit shape of seven "clones," despite its within-"clone" variability, was rather similar oval with a slightly pointed distal end and that of SGS was basically different exhibiting a clear pear shape. The same variation was apparent also in the shape of the stones. Still some slight variation in the diameter (thickness) between both the fruit and the pit could be noted (Fig. 2). Furthermore, the anthocyanin development during maturation in the fruit of SGS started at the distal end, whereas in all other "clones," it developed in the opposite direction starting from the proximal end near the petiole. The difference in maturation apparent in the picture is of no clear significance because the picture represents fruit of a single year (2012) disregarding the specific fruit load on the trees. As will be shown later, the SGS seems to be a true clone or independent cultivar because on the basis of a genome SNP analysis, it was obviously different from all other "clones." Still no significant difference between its leaf form and that of any of the "clones" was apparent.

A comparison of the yield and fruit characteristics of five "clones" (SLO, SAM, SDH, SBU, and SBD) was performed in both the 1974 and the 1996 plots, when the later three additional "clones" were added (SLA, SGS, and SH-1). The data were collected during 5 "on" years starting when the trees were 6 years old and presented as means for that period. Generally the mean performance of the five "clones" during 5 "on" years in the two successive plots (20 years apart) was most similar (Table 2). The difference in yield and fruit characteristics between the different "clones" was also small, although a few significant differences between them were apparent. The mean yield of SLO and SAM during the 5 "on" years was significantly higher in both plots than that of the other three, which did not differ between them. The SLA "clone" only present in Plot B had a similar fruit yield as the three "clones" with the somewhat lower production. The variability in fruit size between the "clones" was slightly different although the tendency was about the same. The fruit on the SLO trees was the largest in both plots and that of SBU the smallest, whereas the fruit of SBD was relatively larger in Plot A than in Plot B. However, the fruit size of all "clones" was larger in the 1996 Plot B than in the earlier planted Plot A (Table 2). The fruit size of the additional "clones" in Plot B was in the same order of magnitude as the others with SGS developing the largest and SLA the smallest

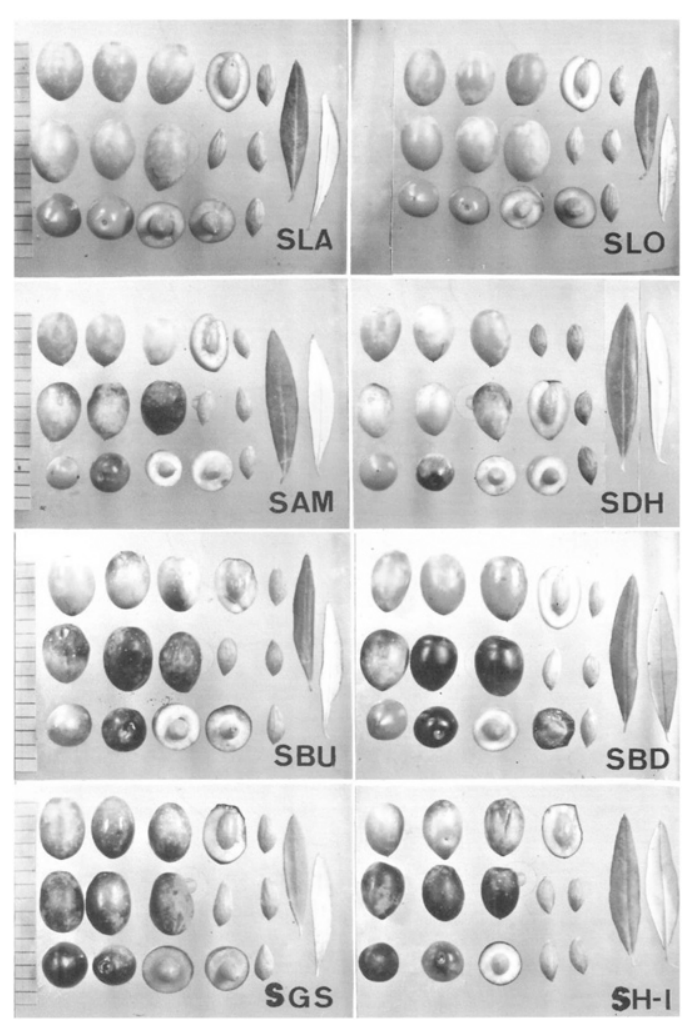

Fig. 2. Fruits, pits, and leaves of eight cv. Souri “clones" grown under intensive irrigated conditions at BetDagan in the center of the Israeli coastal plain in 2012.

Table 2. Mean yield and fruit characteristics of cv. Souri "clones" in two different successive experimental plots during 5 "on" years starting 6 years after planting in each of the plots. ${ }^{2}$

\begin{tabular}{|c|c|c|c|c|c|c|}
\hline & Yield (kg/tree) (a) & Fruit fresh wht (g) (b) & Stone $(\%)(\mathrm{c})$ & Dry wt (\%) (d) & Commercial oil (\%) (e) & Oil/dry wt (\%) (f) \\
\hline "Clones" & \multicolumn{6}{|c|}{ Plot A 1974-94 } \\
\hline SAM & $33.6 \mathrm{a}$ & $2.5 \mathrm{bc}$ & $13.9 \mathrm{a}$ & $47.1 \mathrm{a}$ & $23.9 \mathrm{ab}$ & $59.4 \mathrm{a}$ \\
\hline SBU & $26.5 \mathrm{~b}$ & $2.34 \mathrm{c}$ & $16.9 \mathrm{~b}$ & $51.0 \mathrm{~b}$ & $23.7 \mathrm{ab}$ & $56.8 \mathrm{a}$ \\
\hline \multirow[t]{2}{*}{ SBD } & $24.1 \mathrm{~b}$ & $3.01 \mathrm{a}$ & $15.3 \mathrm{a}$ & $49.8 \mathrm{a}$ & $24.0 \mathrm{ab}$ & $60.1 \mathrm{a}$ \\
\hline & \multicolumn{6}{|c|}{ Plot B 1996-2012 } \\
\hline SDH & $29.8 \mathrm{~b}$ & $3.25 \mathrm{~b}$ & $14.1 \mathrm{a}$ & $47.8 \mathrm{a}$ & $23.3 \mathrm{ab}$ & $57.1 \mathrm{ab}$ \\
\hline SBU & $27.0 \mathrm{~b}$ & $2.55 \mathrm{c}$ & $17.2 \mathrm{~b}$ & $53.9 \mathrm{~b}$ & $23.9 \mathrm{ab}$ & $54.3 \mathrm{ac}$ \\
\hline \multirow[t]{2}{*}{ SBD } & $28.5 \mathrm{~b}$ & $3.21 \mathrm{~b}$ & $15.1 \mathrm{ab}$ & $50.0 \mathrm{ab}$ & $24.0 \mathrm{a}$ & $59.9 \mathrm{ab}$ \\
\hline & \multicolumn{6}{|c|}{ Other local "clones" } \\
\hline SLA & $29.4 \mathrm{~b}$ & $2.81 \mathrm{~cd}$ & $15.3 \mathrm{ab}$ & $44.1 \mathrm{a}$ & $22.8 \mathrm{~b}$ & $51.9 \mathrm{c}$ \\
\hline SGS & & $4.01 \mathrm{a}$ & $15.8 \mathrm{~b}$ & $39.8 \mathrm{a}$ & $25.7 \mathrm{a}$ & $61.0 \mathrm{~b}$ \\
\hline
\end{tabular}

"In Plot A, each "clone" was represented by four trees and in Plot B by three. 
fruits. The relative pit size (\%/fruit) was about the same in all the "clones" and in both plots except for the percent pit in the fruit of SBU, which was higher than the others in both plots. No significant difference in percent dry weight was found between the "clones" in Plot A and in Plot B but for the fruit of the SBU "clone," the percent of dry weight was somewhat higher. This was also the case in Plot A although in that plot, it not significant. The relative oil content on a dry weight basis was the same in all five "clones" and in both plots but higher in fruits of SGS and SH-1 and lower in that of SLA present only in Plot B. The mean percent of commercial oil (on a fresh weight basis) was about the same in all "clones" grown in both plots with only slight differences, although in both plots, the percent of commercial oil was somewhat (not significantly) higher in fruit of SLO and that of SGS in Plot B (Table 2).

The mean fruit size and relative oil content in the fruit of the five cv. Souri "clones" grown in Plot A during 5 "on" and 5 "off" years was compared and the percent change calculated. Yield is not shown as the yield during the "off" years was low and not commercial. As expected, the difference in fruit size was profound reaching more than $50 \%$ in fruits of SAN and SUB but only $30 \%$ to $40 \%$ in the fruits of SLO, SDH, and SBD (Table 3 ).

The differences in the level of the relative oil content between the "on" and "off" years were rather small and varied considerably between the "clones" from $-0.8 \%$ in fruit of SBD to over $6 \%$ for fruit of SDH and SBU. The mean level of oil content was higher in the "off" years than in the "on" ones except in the fruit of SBD (Table 3).

A comparison of some fruit characteristics from young 6-year-old trees of seven cv. Souri "clones" with the fruit on the same trees 12 years later when the trees were 18 years old was performed in Plot B. Only fruit from trees with a relative similar fruit load were used for the comparison. The general mean of fruit size, percent pit, and fruit coloration of fruit from all seven "clones" on the young and mature trees was rather similar. At the same time, the percent pericarp dry weight and the relative oil content per fresh fruit were higher in the older trees. The percent of oil on a dry weight basis showed an opposite trend. However, for most "clones," no uniformity of the different fruit characteristics from the young and mature trees were apparent (data not shown). As a result of the divers distribution and variability between the fruit characters from the 6- and 18-year-old trees of each "clone," no predictability on future performance was possible based on that of the young trees.

The growth of the seven cv. Souri "clones" in Plot B was evaluated in Winter 2012-13, 18 years after the orchard was established, by determining the circumferences of the trunks. Five of the irrigated cv. Souri "clones," SLD, SBU, SBD, SLA, and SH-1, reached a similar size with a trunk circumference of 75 to $85 \mathrm{~cm}$. The mean trunk size of the SDH "clone" was significantly thinner and that of SAM thicker (Fig. 3). It should be noted even though these differences were less apparent in the size of the canopy (data not shown).

Finally, all the studied cv. Souri "clones" were analyzed for the level of their genetic identity using both SSR and SNPs methodologies including also a cv. Nabali clone as a reference to another morphologically similar autochthonous cultivar. Using 138 SNPs entries, all the cv. Souri "clones" analyzed showed high uniformity with only the SGS differing significantly from all the others as well as the cv. Nabali exhibiting a clearly different DNA combination (Fig. 4A). Based on the SSR analysis using 16 SSR loci, some more defined differences and grouping of the "clones" were visible (Supplemental Table 1). The SLO and SLA seemed most close to each other and also SDH and SAM. These two pairs were rather close to each other and also to SBU and could be considered one group (Fig. 4B). The SGS was slightly out of this group but still rather close to it. The SSR analysis indicated a separate group for the SH-1 and cv. Nabali, which is rather odd, whereas next to it, although independent and quite distant from all other "clones," we found the DNA makeup of SBD.

Table 3. The relative difference of the mean fruit size and oil content of five cv. Souri "clones" during 5 "on" and 5 "off" years in Plot A starting when the trees were 6 years old. ${ }^{z}$

\begin{tabular}{lccc}
\hline & "On" year & "Off" year & Difference (\%) \\
\cline { 2 - 4 } & \multicolumn{3}{c}{ Mean fruit size $(\mathrm{g})$} \\
\hline SLO & $3.05 \mathrm{a}$ & $4.16 \mathrm{a}$ & +36.4 \\
SAM & $2.50 \mathrm{bc}$ & $3.81 \mathrm{abc}$ & +52.4 \\
SDH & $2.73 \mathrm{ab}$ & $3.77 \mathrm{abc}$ & +38.1 \\
SBU & $2.34 \mathrm{c}$ & $3.60 \mathrm{bc}$ & +53.8 \\
SBD & $3.01 \mathrm{a}$ & $3.98 \mathrm{ab}$ & +32.2 \\
Mean & 2.73 & 3.86 & +41.4
\end{tabular}

\begin{tabular}{llll} 
& \multicolumn{3}{c}{ Mean relative oil content (\%) } \\
SLO & $25.5 \mathrm{a}$ & $26.0 \mathrm{a}$ & +2.0 \\
SAM & $23.9 \mathrm{ab}$ & $24.8 \mathrm{a}$ & +3.8 \\
SDH & $23.1 \mathrm{~b}$ & $24.5 \mathrm{a}$ & +6.1 \\
SBU & $23.7 \mathrm{ab}$ & $25.2 \mathrm{a}$ & +6.4 \\
SBD & $24.0 \mathrm{ab}$ & $23.8 \mathrm{a}$ & -0.8 \\
Mean & 24.0 & 24.9 & +3.5
\end{tabular}

${ }^{2}$ The results are based on four trees of each "clone."

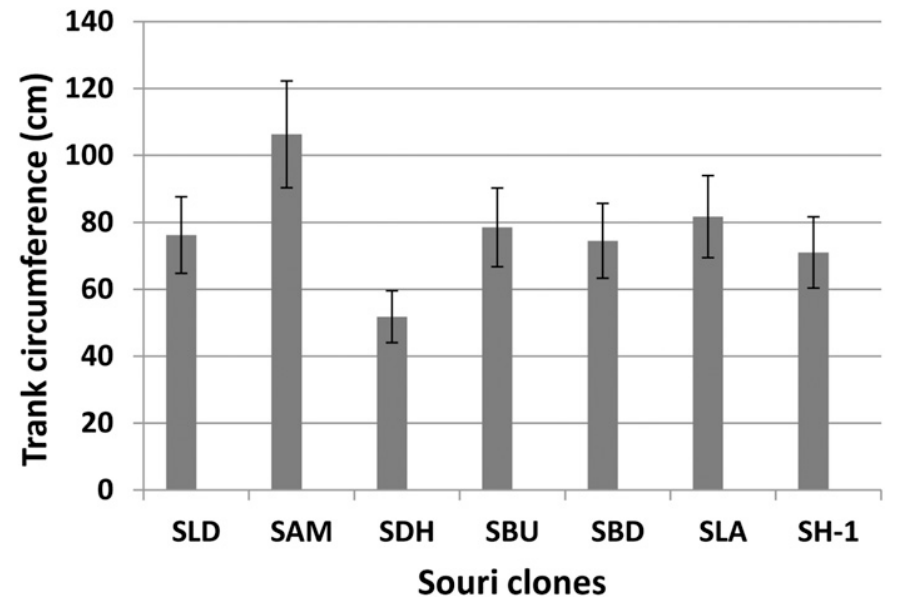

Fig. 3. Trunk circumference of seven cv. Souri "clones" grown under intensive drip irrigated conditions 18 years after planting at Bet-Dagan in the center of the Israeli coastal plain.

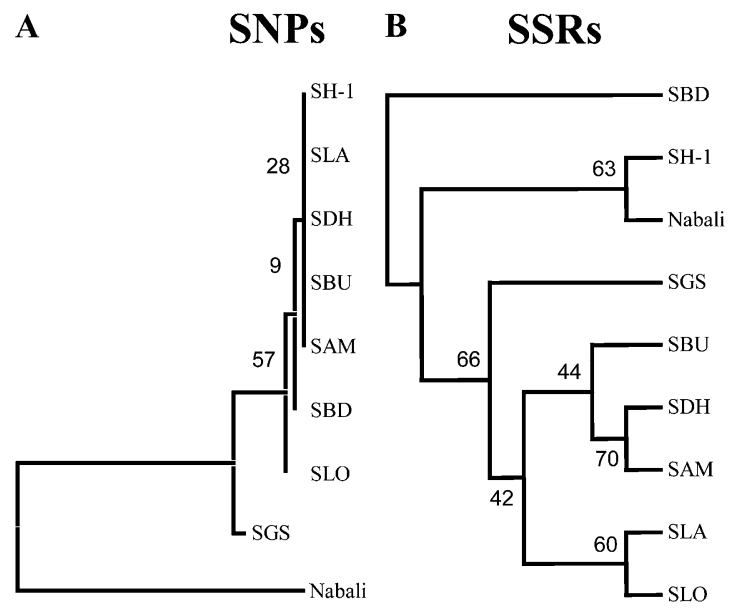

Fig. 4. Illustration of the genetic relationship between eight cv. Souri "clones" and cv. Nabali based on DNA analysis using single nucleotide polymorphisms (SNPs) (A) and simple sequence repeats (SSRs) (B). Numbers on nodes are bootstrap values out of 100 . 


\section{Discussion}

The cv. Souri is a cultivar highly resistant to drought and limited edaphic conditions and is the major cultivar in the rain-fed orchards in Israel. This adaptation to harsh growing conditions over many decades is accompanied with a limitation to respond to intensification and irrigation. Because the fruit of the cv. Souri is highly appreciated by consumers both for its oil and table olives, clonal selection was initiated aiming to identify lines more responsive to intensification imperative for economical reasons. Similar clonal selection was performed successfully within traditional cultivars in various countries (Belaj et al., 2004; Oueslati et al., 2009; Tous et al., 1998, 2011). Irrigation was previously shown to double the fruit yield by increasing the fruit bearing surface, but mainly as a result of an increase in fruit size. It is important to note that the reduction in the relative oil content when grown on no limiting soils is small when harvested at a similar maturation stage of the fruits (Lavee and Wodner, 2004). Eight cv. Souri lines for intensive cultivation were selected mainly by nurseries of which seven are grown commercially. However, the use of these lines or so-called "clones" to the present is rather arbitrarily with no real supporting data. In the present study, we performed a long-term comparison among most of these "clones." Comparing the seasonal rate of fruit growth and oil accumulation of three "clones," SLO, SAM, and SBD, revealed slight differences among them. However, the differences were small with fruit growth and oil accumulation developed independently except for SLO, which responded better to the intensive condition than the other two "clones." In two successive experimental plots for $\approx 20$ years, the mean fruit yield of SLO and SAM during the "on" years was also slightly, although significantly, higher than that of the other three "clones," SDH, SBU, and SBD, compared in those two plots. This was the case also for the commercial oil content in fruit of SLO in both plots. Although the differences in the mean fruit yield and oil content between the tested "clones" in the "on" years of both plots were rather small, the general trend of performance of the tested clones was stable and about the same in both plots. Some significant differences were also found in fruit size, percent stone, and percent dry material, particularly in fruit of SBU. Despite the small but stable differences in performance and fruit characters of the different "clones," the DNA makeup based on SNPs was most similar for all "clones" except for SGS, which according to this analysis could be considered a true unique clone of 'Souri' or even a closely related independent variety. This could be the case also on the basis of the SSR analysis, which showed somewhat more defined differences between the DNA of the different tested cv. Souri "clones." The different mutational properties of SSR and SNP markers result in differences in heterozygosities and allele frequencies that have implications regarding their use in assessing phylogenetic relationships and genetic diversity (Ellegren, 2004; Li et al., 2002). It should be noted, however, that the uniformity of long-term performance of the different "clonal" trees could not be deducted from their behavior during the first full production year of the young trees. Translation of the performance of the young trees to the level of performance in general or a single future year in particular is not possible as shown by comparing the performance of young trees 6 years after planting with the performance of the same trees during a single year 12 years later.

Including the "off" year fruit data in the performance calculation of the "clones" would as expected make a major difference in the fruit size data because the mean fruit size during five "off" years in Plot A was $\approx 40 \%$ larger than in the "on" years. However, the mean relative oil content in the "on" and "off" years differed only slightly with a maximal increase of $\approx 6 \%$ in fruit of SDH and SBU. Because the yield in the "off" years of all the cv. Souri "clones" was very low, the data of the "off" years were not included in the comparison. The cumulative growth of the different "clones" on the basis of the trunk circumference was the same for five of the "clones" but there was a considerable different for two, SAM and SDH, with the first being larger and the second significantly smaller than the other five despite that these two "clones" appeared as a most closely related pair in the SSR analysis of the DNA identity.

To conclude, it seems that neither on tree performance and fruit morphology nor on the basis of the DNA analysis can a clear-cut decision regarding the nature and of the differences between the tested cv. Souri "clones" can be drawn. On the basis of two successive plots, each was maintained for $\approx 20$ years. It is possible to conclude that those differences identified between the "clones" are stable at least under the Bet-Dagan irrigated growing conditions. The SNP analysis of the genome indicates high identity of the "clones" except for the SGS one; however, SSR analysis of the DNA from the various "clones" revealed some differences between them. We assume that as a result of the level of differences or identities, we could consider identifying the SGS, SLO, and SBU as true clones, whereas the others should be considered as one group with no genetic slight changes occurring occasionally in the orchard.

\section{Literature Cited}

Belaj, A., L. Rallo, I. Trujillo, and L. Baldoni. 2004. Using RAPD and AFLP markers to distinguish individuals obtained by clonal selection of 'Arbequina' and 'Manzamila de Sevilla' olive. HortScience 39:1566-1570.

Biton, I., S. Shevtsov, O. Ostersetzer, Y. Mani, S. Lavee, B. Avidan, and G. Ben-Ari. 2012. Genetic relationships and hybrid vigour in olive
(Olea europaea L.) by microsatellites. Plant Breed. 131:767-774.

Bowcock, A.M., A. Ruizlinares, J. Tomfohrde, E. Minch, J.R. Kidd, and L.L. Cavallisforza. 1994. High-resolution of human evolutionary trees with polymorphic microsatellites. Nature 368:455-457.

Ellegren, H. 2004. Microsatellites: Simple sequences with complex evolution. Nat. Rev. Genet. 5:435-445.

Goor, A., 1948. Olive cultivars in Israel. Hassade Press, Tel-Aviv, Israel. p. 32 [in Hebrew].

Grattan, S.R., M.J. Berenquer, J.H. Connell, V.S. Polito, and P.M. Vossen. 2006. Olive oil production as influenced by different quantities of applied water. Agr. Water Mgt. 85:133-140.

Greven, M., S. Neal, S. Green, B. Dichio, and B. Clothier. 2009. The effects of drought on the water use, fruit development and oil yield from young olive trees. Agr. Water Mgt. 96:15251531 .

Jbara, G., A. Jawhar, Z. Bido, G. Cardone, A. Dragotta, and F. Famiani. 2010. Fruit and oil characteristics of the main Syrian olive cultivars. Ital. J. Food Sci. 22:395-400.

Lavee, S. 2007. Biennial bearing in olive (olea europaea). Annales Series Historia Naturalis 17:101-112.

Lavee, S., N. Avidan, and Z. Wiesman. 1999 Genetic variation within the Nabali baladi cultivar of the West Bank. Acta Hort. 474:129-132.

Lavee, S., A. Singer, A. Haskal, B. Avidan, and M Wodner. 2008. Diversity in performance between trees within the traditional Souri olive cultivar (Olea europaea L) in Israel under rain fed conditions. Olivae 109:33-45.

Lavee, S. and M. Wodner. 2004. The effect of yield, harvest time and fruit size on the oil content in fruits of irrigated olive trees (Olea europaea). Sci. Hort. 99:267-277.

Li, Y.-C., A.B. Korol, T. Fahima, A. Beiles, and E. Nevo. 2002. Microsatellites: Genomic distribution, putative functions and mutational mechanisms: A review. Mol. Ecol. 11:24532465 .

Odong, T.L., J. Heerwaarden, J. Jansen, T.J.L. Hintum, and F.A. Eeuwijk. 2011. Determination of genetic structure of germplasm collections: Are traditional hierarchical clustering methods appropriate for molecular marker data? Theor. Appl. Genet. 123:195-205.

Omar, R.J. 2012. Morphological and genetical characterisation of the main Palestinian olive (Olea europaea L.) cultivars. An-Najah National University, Master of Plant Production.

Oueslati, I., W. Taamalli, F.M. Haddada, H. Manai, A. Trigui, and M. Zarrouk. 2009. Improving the fatty acid composition of 'Chemlali' virgin olive oil through clonal selection. J. Hort. Sci. Biotechnol. 84:155-160.

Paradis, E., J. Claude, and K. Strimmer. 2004. APE: Analyses of phylogenetics and evolution in R language. Bioinformatics 20:289-290.

Popescu, A.-A., K.T. Huber, and E. Paradis. 2012. ape 3.0: New tools for distance-based phylogenetics and evolutionary analysis in R. Bioinformatics 28:1536-1537.

Tous, J., A. Romero, J. Francisco Hermoso, and A. Ninot. 2011. Mediterranean clonal selections evaluated for modern hedgerow olive oil production in Spain. Calif. Agr. 65:34-38.

Tous, J., A. Romero, J. Plana, and J. Aranburu. 1998. Seleccion clonal de la variedad de olive 'Arbequina' Presentacion del clon IRTA-1-18. Phytoma 102:15-28. 
Supplemental Table 1. Genetic distances between the different 'clones' based on both SSR and SNPs.

\begin{tabular}{|c|c|c|c|c|c|c|c|c|c|}
\hline & \multicolumn{9}{|c|}{ SSRs } \\
\hline & Nabali & SAM & SBD & SBU & $\mathrm{SDH}$ & SGS & SH-1 & SLR & SLO \\
\hline \multicolumn{10}{|l|}{ Nabali } \\
\hline SAM & 0.27 & & & & & & & & \\
\hline SBD & 0.13 & 0.13 & & & & & & & \\
\hline SBU & 0.27 & 0.07 & 0.13 & & & & & & \\
\hline $\mathrm{SDH}$ & 0.27 & 0 & 0.13 & 0.07 & & & & & \\
\hline SGS & 0.54 & 0.38 & 0.42 & 0.42 & 0.38 & & & & \\
\hline SH-1 & 0.2 & 0.3 & 0.2 & 0.3 & 0.3 & 0.54 & & & \\
\hline SLR & 0.23 & 0.05 & 0.14 & 0.09 & 0.05 & 0.4 & 0.18 & & \\
\hline \multirow[t]{3}{*}{ SLO } & 0.29 & 0.07 & 0.14 & 0.11 & 0.07 & 0.36 & 0.32 & 0 & \\
\hline & \multicolumn{9}{|c|}{ SNPs } \\
\hline & Nabali & SAM & SBD & $\mathrm{SBU}$ & $\mathrm{SDH}$ & SGS & SH-1 & SLR & $\overline{\text { SLO }}$ \\
\hline \multicolumn{10}{|l|}{$\overline{\text { Nabali }}$} \\
\hline SAM & 0.28 & & & & & & & & \\
\hline SBD & 0.28 & 0.02 & & & & & & & \\
\hline SBU & 0.29 & 0.03 & 0.03 & & & & & & \\
\hline $\mathrm{SDH}$ & 0.28 & 0 & 0.02 & 0.03 & & & & & \\
\hline SGS & 0.34 & 0.19 & 0.19 & 0.18 & 0.19 & & & & \\
\hline SH-1 & 0.29 & 0.01 & 0.02 & 0.04 & 0.01 & 0.21 & & & \\
\hline SLR & 0.28 & 0 & 0.02 & 0.03 & 0 & 0.19 & 0.01 & & \\
\hline SLO & 0.3 & 0.04 & 0.04 & 0.03 & 0.04 & 0.19 & 0.04 & 0.04 & \\
\hline
\end{tabular}

$\mathrm{SSRs}=$ simple sequence repeats; SNPs $=$ single nucleotide polymorphisms. 